\title{
Compressive strength of tungsten mine waste- and metakaolin- based geopolymers
}

\author{
Ali Nazari ${ }^{a, *}$, F. Pacheco Torgal ${ }^{b}$, A. Cevik ${ }^{c}$, J.G. Sanjayan ${ }^{a}$ \\ ${ }^{a}$ Centre for Sustainable Infrastructure, Faculty of Science, Engineering and Technology, Swinburne University of Technology, Hawthorn, Victoria 3122, Australia \\ ${ }^{\mathrm{b}}$ University of Minho, C-TAC Research Centre, Guimarães, Portugal \\ ${ }^{\mathrm{c}}$ Gaziantep University, Civil Engineering Department, Gaziantep, Turkey
}

Received 19 September 2013; accepted 12 November 2013

Available online 23 November 2013

\begin{abstract}
Neuro-fuzzy approach has been successfully applied to a wide range of civil engineering problems so far. However, this is limited for geopolymeric specimens. In the present study, compressive strength of different types of geopolymers has been modeled by adaptive neuro-fuzzy interfacial systems (ANFIS). The model was constructed by 395 experimental data collected from the literature and divided into $80 \%$ and $20 \%$ for training and testing phases, respectively. Curing time, $\mathrm{Ca}(\mathrm{OH})_{2}$ content, $\mathrm{NaOH}$ concentration, mold type, aluminosilicate source and $\mathrm{H}_{2} \mathrm{O} / \mathrm{Na}_{2} \mathrm{O}$ molar ratio were independent input parameters in the proposed model. Absolute fraction of variance, absolute percentage error and root mean square error of $0.94,11.52$ and 14.48 , respectively in training phase and $0.92,15.89$ and 23.69 , respectively in testing phase of the model were achieved showing the relatively high accuracy of the proposed ANFIS model. By the obtained results, a comparative study was performed to show the interaction of some selected factors on the compressive strength of the considered geopolymers. The discussions findings were in accordance to the experimental studies and those results presented in the literature.
\end{abstract}

(c) 2013 Elsevier Ltd and Techna Group S.r.l. All rights reserved.

Keywords: Geopolymer; Modeling; Compressive strength; Aluminosilicate source; $\mathrm{NaOH}$ concentration

\section{Introduction}

Geopolymers, a class of inorganic polymers having an amorphous structure consisting of $\left[\mathrm{SiO}_{4}\right]^{4-}$ and $\left[\mathrm{AlO}_{4}\right]^{5-}$ tetrahedral which share the entire corners with each other through oxygen atoms, are generally produced by mixing of an raw aluminosilicate source in the form of a powder with an alkaline silicate solution followed by curing [1,2]. On account of production by little carbon emmision, geopolymers are one of the primary replacements for ordinary Portland cement (OPC) whose production requires large amounts of energy and emits much anthropogenic $\mathrm{CO}_{2}[2,3]$. Various aluminosilicate sources are used to date for production environmentally friendly geopolymers. Kaolin and metakaolin [4-8], fly ash [9-14] and different types of slags and muds $[10,15-18]$ are among the most used aluminosilicate sources for geopolymerization.

\footnotetext{
*Corresponding author. Tel.: +6192148370.

E-mail address: alinazari@swin.edu.au (A. Nazari).
}

Although such soft-computing techniques as artificial neural networks (ANNs), genetic programming (GP) and adaptive neuro-fuzzy interfacial systems (ANFIS) have been successfully applied to a wide range of civil engineering problems so far [1930], this is very limited in geopolymers field as a new type highperformance construction materials and is only limited to the previous works (see [31-33] for example). In the previous work [31], compressive strength of geopolymers with different aluminosilicate source was modeled by ANNs. It was reported that ANNs are capable to predict the compressive strength of geopolymers by a suitable accuracy. In the present study, ANFIS has been utilized to predict the compressive strength of the previously modeled geopolymers. Through using fuzzy sets and a linguistic model incorporating a set of IF-THEN fuzzy rules, ANFIS integrates the human-like reasoning approach of fuzzy systems. Besides the ability to petition for interpretable IF-THEN rules, being universal approximators is the main strength of ANFIS approximations [34].

To construct the ANFIS model in the present study, curing time (days), $\mathrm{Ca}(\mathrm{OH})_{2}$ content (wt $\%$ ), $\mathrm{NaOH}$ concentration, 
mold type, aluminosilicate source and $\mathrm{H}_{2} \mathrm{O} / \mathrm{Na}_{2} \mathrm{O}$ molar ratio were considered as independent input parameters and the compressive strength of the investigated geopolymers as independent target value. The experimental databases were divided into training (80\%) and testing (20\%) sets and modeled by the proposed ANFIS model which was constructed by a total of 128 rules.

\section{Data collection}

The collected data were same as those used in the previous work [31]. Three main series of geopolymers each made from a certain aluminosilicate source were considered in this study same as the previous work:

(1) The first series of samples were the compressive specimens made from tungsten mine wastes. Tungsten mine waste mud which was subjected to a thermal treatment, the fine aggregate which was crushed sand from the same mine, distilled water, the sodium hydroxide flakes, sodium silicate solution and calcium hydroxide were the materials used to produced geopolymeric compressive specimens using $50 \times 50 \times 50 \mathrm{~mm}^{3}$ cubic molds, according to ASTM C109. The complete preparation method of the considered geopolymers has been given in Ref. [35].

(2) Metakaolin-based geopolymers made from metakaolin, calcium hydroxide, sodium hydroxide, sodium silicate solution, superplasticizer, sand and distilled water was used to dissolve the sodium hydroxide flakes [12]. Alkaliactivated mortars were a mixture of aggregates, metakaolin, calcium hydroxide and alkaline silicate solution were poured into $160 \times 40 \times 40 \mathrm{~mm}^{3}$ cubic specimens according to EN 1015-11. The preparation method for compressive strength tests has been presented in Ref. [8].

(3) The third group of geopolymers made by tungsten waste mud was consisted of aggregates, waste mud, calcium hydroxide, alkaline silicate solution and water in a similar way to the method described above for the data gathered from Ref. [35].

\section{Fuzzy logic}

A wide range of covering engineering, process control, image processing, pattern recognition and classification, management, economics and decision making has been considered over the last decade by fuzzy logic, an interesting method invented by Lotfi Zadeh [36] in 1965 [37].

Fuzzy systems can be defined as rule-based systems that are constructed from a collection of linguistic rules which can represent any system with accuracy, i.e., they work as universal approximators. The rule-based system of the fuzzy logic theory uses linguistic variables as its antecedents and consequents where antecedents express an inference or the inequality, which should be satisfied and consequents are those, which we can infer, and is the output if the antecedent inequality is satisfied. The fuzzy rule-based system is actually

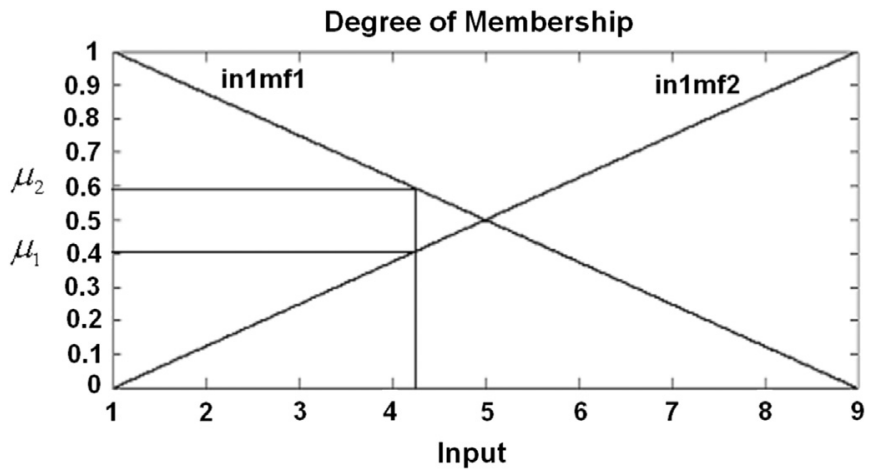

Fig. 1. Input data membershipvalues [39].

an IF-THEN rule-based system, given by, IF antecedent, THEN consequent [38].

FL operations are based on fuzzy sets where the input data may be defined as fuzzy sets or a single element with a membership value of unity. The membership values $\left(\mu_{1}\right.$ and $\mu_{2}$ ) are found from the intersections of the data sets with the fuzzy sets as shown in Fig. 1 which illustrates the graphical method of finding membership values in the case of a single input [39].

A fuzzy set contains elements which have varying degrees of membership in the set, unlike the classical or crisp sets where a member either belongs to that set or does not ( 0 or 1$)$. However, a fuzzy set allows a member to have a varying degree of membership which can be mapped into a function or a universe of membership values [40].

The implementation of fuzzy logic to real applications considers the following steps [40]:

1. Fuzzification which requires conversion of classical data or crisp data into fuzzy data or Membership Functions (MFs).

2. Fuzzy Inference Process which connects membership functions with the fuzzy rules to derive the fuzzy output.

3. Defuzzification which computes each associated output.

\subsection{Neuro-fuzzy systems}

Fuzzy systems can also be connected with Neural Networks to form neuro-fuzzy systems which exhibit advantages of both approaches. Neuro-fuzzy systems combine the natural language description of fuzzy systems and the learning properties of neural networks. Various neuro fuzzy systems have been developed that are known in literature under short names. Adaptive Network-based Fuzzy Inference System (ANFIS) developed by Jang [41], is one of these neuro-fuzzy systems which allow the fuzzy systems to learn the parameters using adaptive back propagation learning algorithm [37]. Mainly three types of fuzzy inference systems have been widely employed in various applications: Mamdani, Sugeno and Tsukamoto fuzzy models. The differences between these three fuzzy inference systems compromise as a result of their fuzzy rules, as well as 
their aggregation and defuzzification procedures which differ accordingly [41]. In this study, the Sugeno FIS is used where each rule is defined as a linear combination of input variables. The corresponding final output of the fuzzy model is simply the weighted average of each rule's output. A Sugeno FIS consisting of two input variables $x$ and $y$, for example, a one output variable $f$ will lead to two fuzzy rules:
Rule 1: If $x$ is $A_{1}, y$ is $B_{1}$ then $f_{1}=p_{1} x+q_{1} y+r_{1}$

Rule 2: If $x$ is $A_{2}, y$ is $B_{2}$ then $f_{2}=p_{2} x+q_{2} y+r_{2}$

where $p_{i}, q_{i}$, and $r_{i}$ are the consequent parameters of $i$ th rule. $A_{i}, B_{i}$ and $C_{i}$ are the linguistic labels which are represented by fuzzy sets shown in Fig. 2 [41].

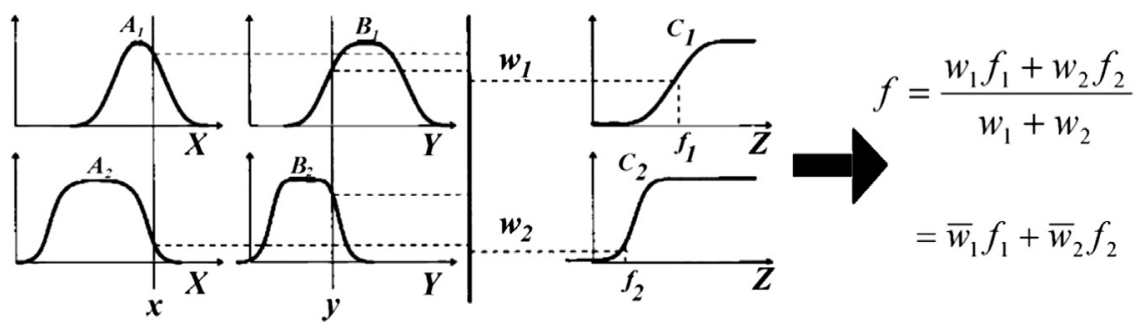

Fig. 2. The Sugeno fuzzy model [41].
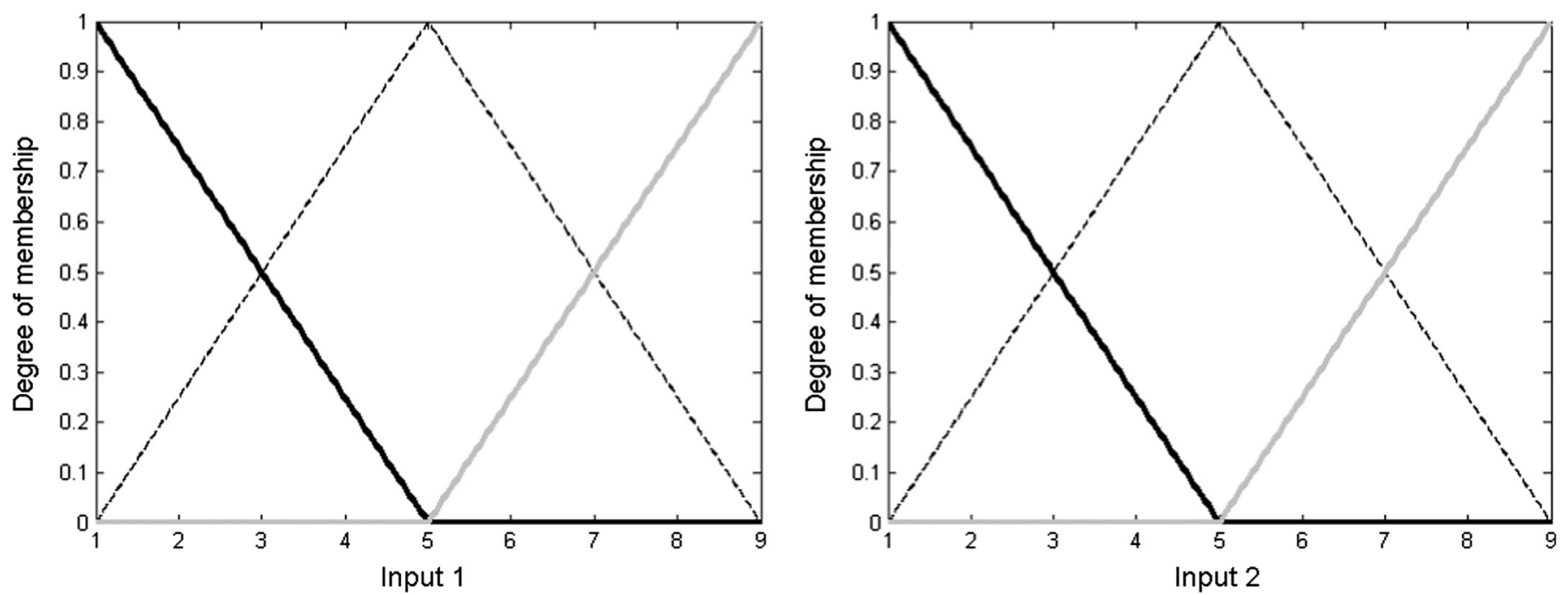

Fig. 3. Initial membership functions [42].
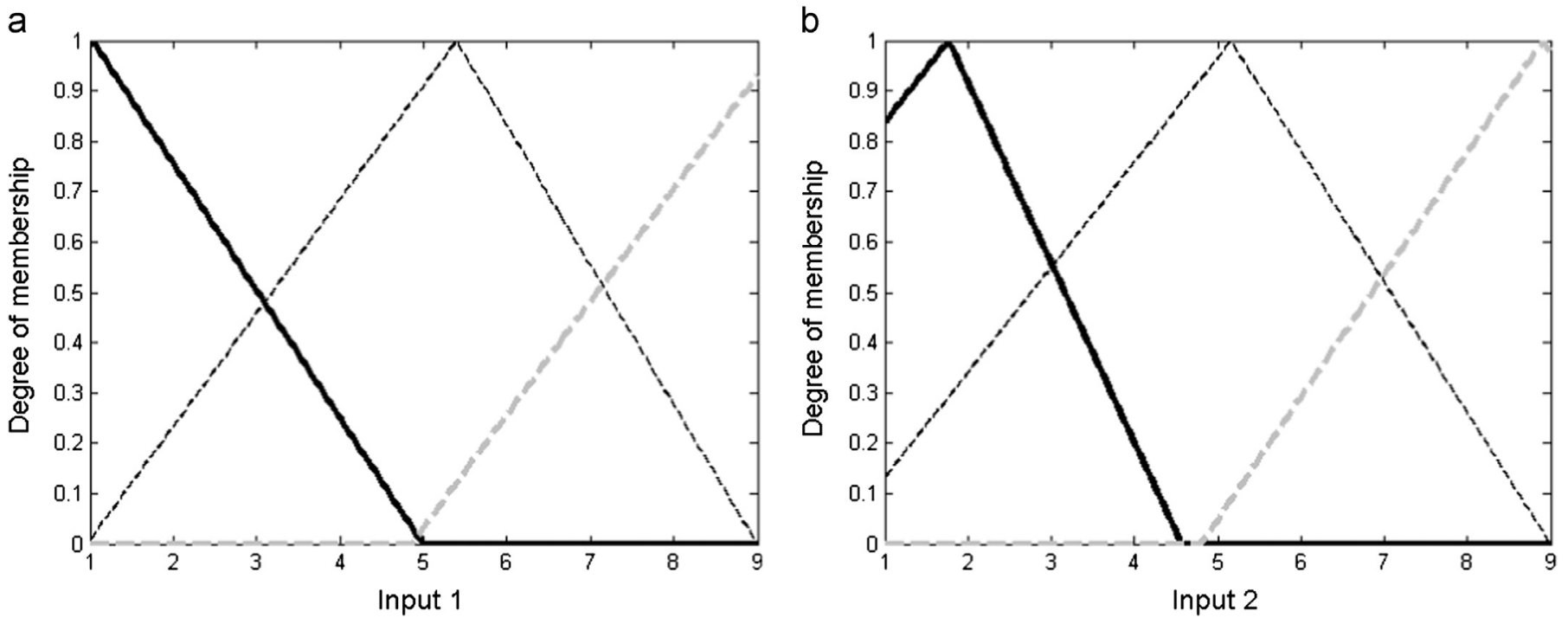

Fig. 4. Final membership functions [42]. 


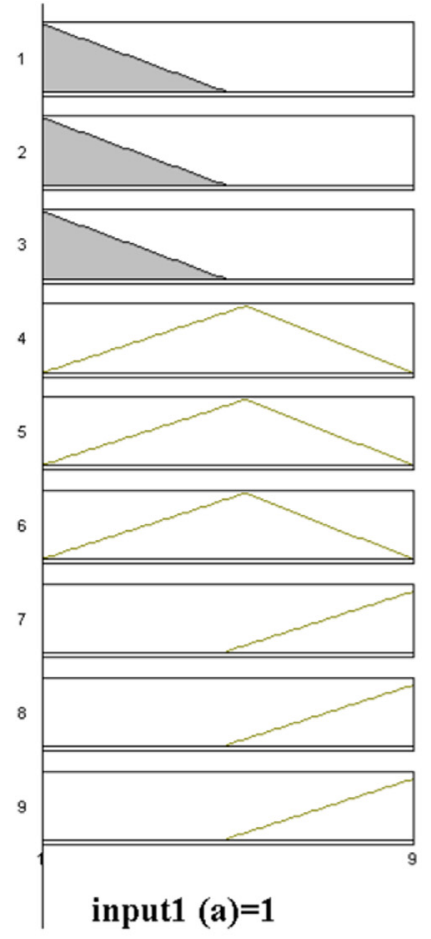

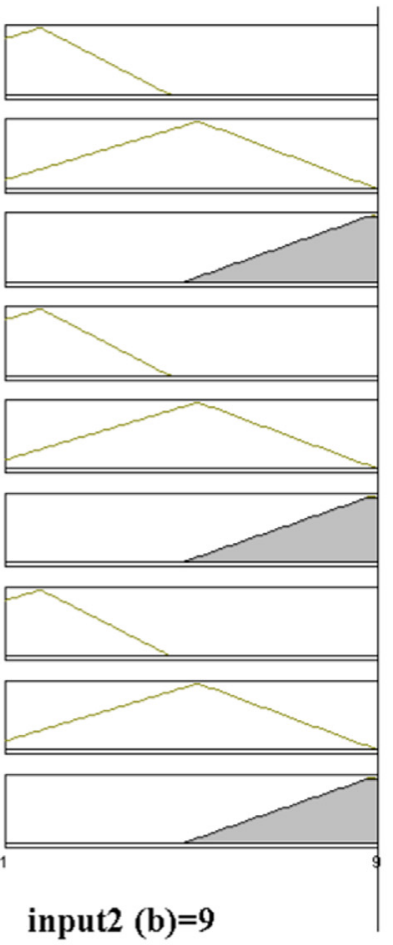

input $2(b)=9$
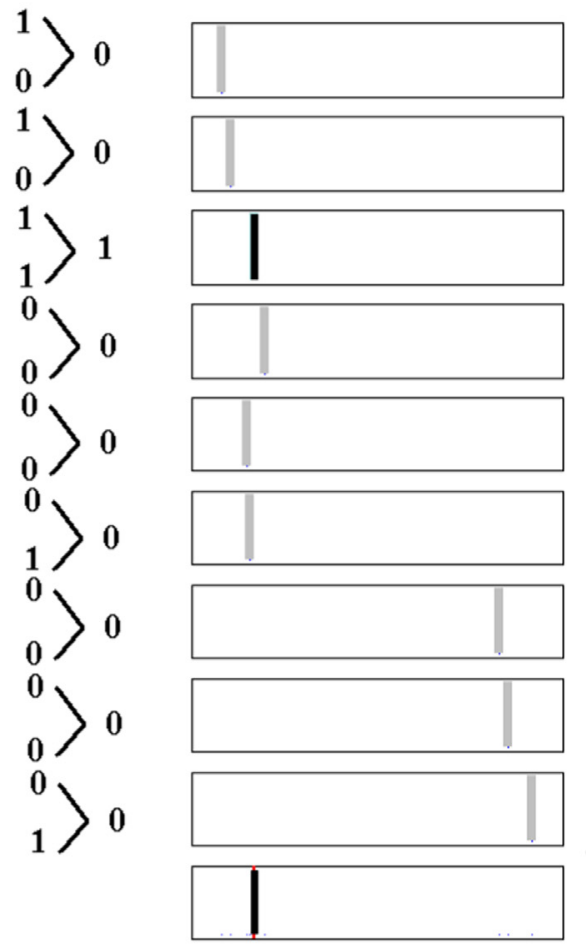

$[-1.95] \times 0=0$

$[20.9] \times 0=0$

$[82] \times 1=82$

$[111.1] \times 0=0$

$[62.2] \times 0=0$

[71.9] $\mathbf{x} 0=0$

$[727] \times 0=0$

$[750] \times 0=0$

$[810] \times 0=0$

$+$

82

output $=\mathbf{8 2}$

Fig. 5. Fuzzy inference diagram [42].

\subsection{Solving a simple problem with ANFIS}

To illustrate how ANFIS works for function approximation, let us suppose one is given a sampling of the numerical values from the simple function below [42]:

$y_{i}=a^{3}+b^{2}$

where $a$ and $b$ are independent variables chosen over random points in the real interval $[1,9]$. In this case, a sample of data in the form of 17 pairs $\left(a, b, y_{i}\right)$ is given where $x_{i}$ is the value of the independent variable in the given interval $[1,9]$ and $y_{i}$ is the output of the function given in Eq. (1) and presented in Table 2. The aim is to construct the ANFIS model fitting those values within minimum error for Eq. (1) by using the simplest ANFIS model that is available where the number of rules is 2 for each variable and the type of output membership function is constant. Initial and final membership values of rules for each input are given in Figs. 3 and 4, respectively. Suppose one will find the output for input values of 1 and 9. The inference diagram of the proposed ANFIS model is given in Fig. 5 for input values of 1 and 9 with corresponding values of output membership which is chosen as constant. For the first input which is 1 the value of the membership function is observed to be 1 shown on left side of Fig. 7. For the second input which is 9 the value of the membership function is observed to be 1 again shown on left side of Fig. 7. Thus the final output will be $82 \times 1=82$.

The exact result for $a=1$ and $b=9$ from Eq. (1) will be $y=1^{3}+9^{2}=82$.
Table 1

Features of the proposed ANFIS model.

\begin{tabular}{ll}
\hline Type & SUGENO \\
\hline Aggregation method & Maximum \\
Defuzzification method & Weighted average \\
Input membership function type & Gaussian \\
Output membership function type & Constant \\
\hline
\end{tabular}

Table 2

Statistical parameters of testing and training sets and overall results of ANFIS model for compressive strength.

\begin{tabular}{lccc}
\hline & Training set & Testing set & Total set \\
\hline MSE & 14.48 & 23.69 & 16.32 \\
MAPE & 11.52 & 15.89 & 12.40 \\
$R^{2}$ & 0.94 & 0.92 & 0.94 \\
MEAN & 1.00 & 1.03 & 1.00 \\
COV & 0.17 & 0.23 & 0.19 \\
\hline
\end{tabular}

The main aim of this study is the neuro-fuzzy modeling compressive strength of geopolymers produced by different aluminosilicate sources based on an experimental database. Compressive strength of geopolymers will be obtained as a function of curing time (days), $\mathrm{Ca}(\mathrm{OH})_{2}$ content (wt $\left.\%\right), \mathrm{NaOH}$ concentration (M), mold type, aluminosilicate source and $\mathrm{H}_{2} \mathrm{O} / \mathrm{Na}_{2} \mathrm{O}$ molar ratio. The experimental database was divided into training (80\%) and testing (20\%) sets. The ANFIS model is constructed with training sets and the accuracy is verified by testing sets which the ANFIS model faces for the first time. 


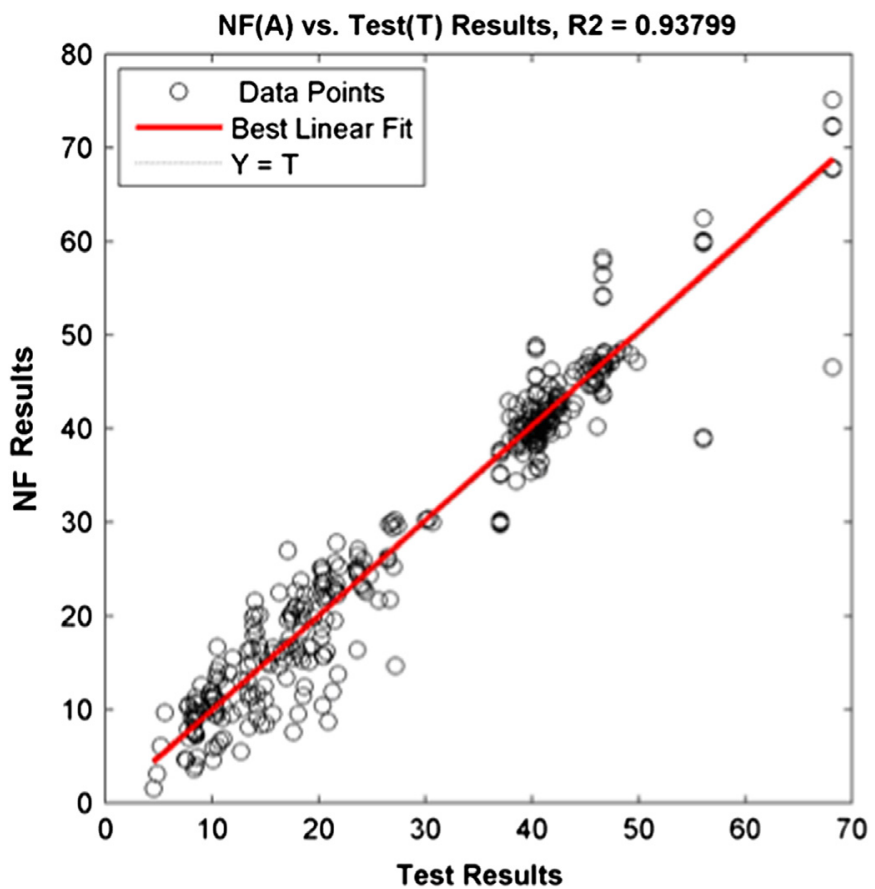

Fig. 6. Performance of ANFIS model with respect to experimental results for compressive strength.
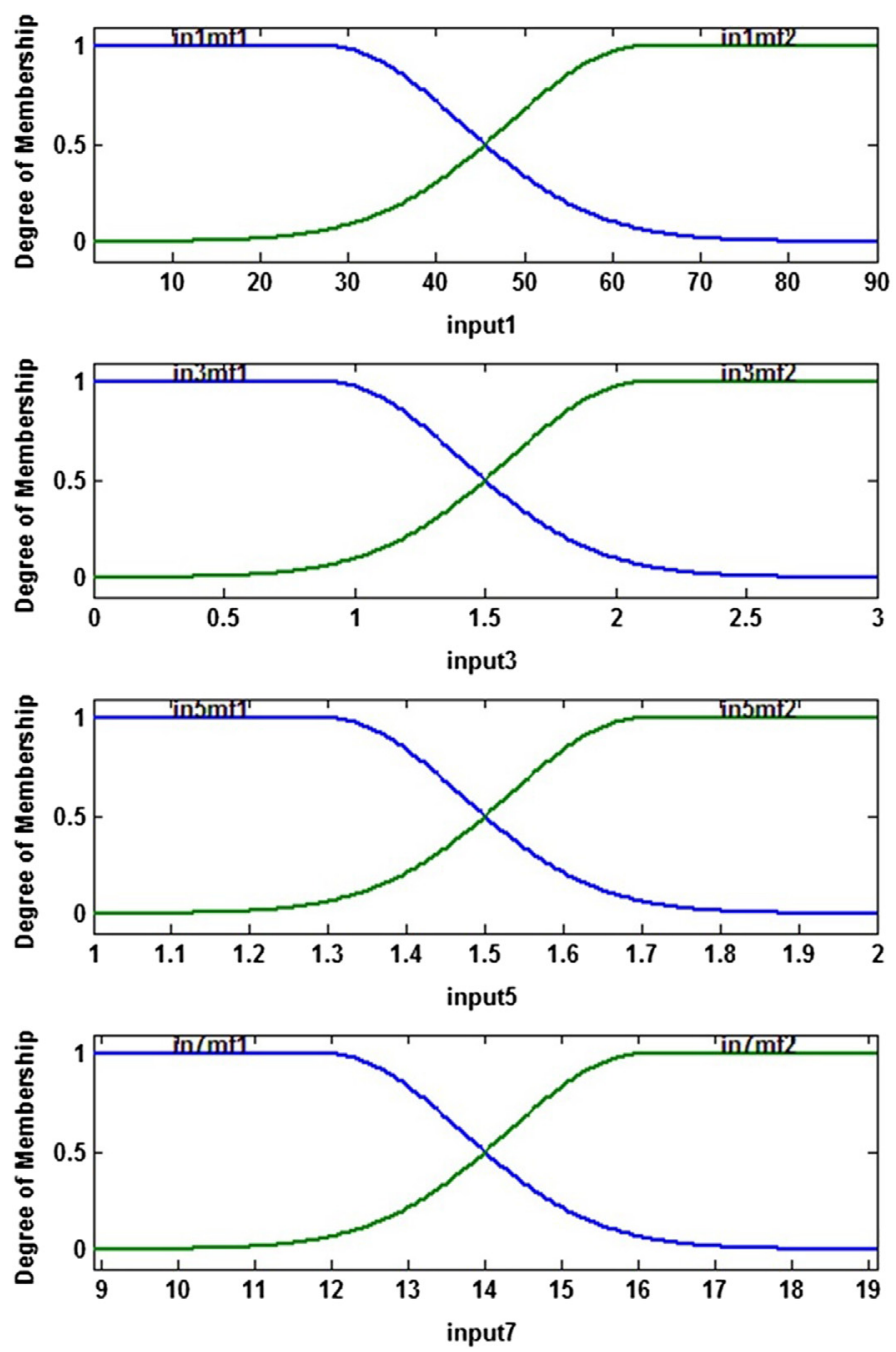

The proposed ANFIS models use Gaussian membership function with 2 rules. The output membership function is chosen as constant value. Features of the proposed ANFIS model are given in Table 1. Statistical parameters of testing and training sets and overall results of the ANFIS model are presented in Table 2. The overall correlation of the ANFIS model can be seen in Fig. 6. ANFIS results are observed to be very close to actual results. The initial and final membership functions of inputs for compressive strength are presented in Figs. 7 and 8, respectively. The fuzzy inference diagram is presented in Fig. 9 with a total of 128 rules.

\section{Results and discussion}

Absolute fraction of variance $\left(R^{2}\right)$, the absolute percentage error (MAPE) and the root mean square error (MSE) were used in this study to represent the error arose during the training and testing in the proposed ANFIS model and they were calculated by Eqs. (2), (3) and(4) respectively [43]:

$R^{2}=1-\left(\frac{\sum_{i}\left(t_{i}-o_{i}\right)^{2}}{\sum_{i}\left(o_{i}\right)^{2}}\right)$
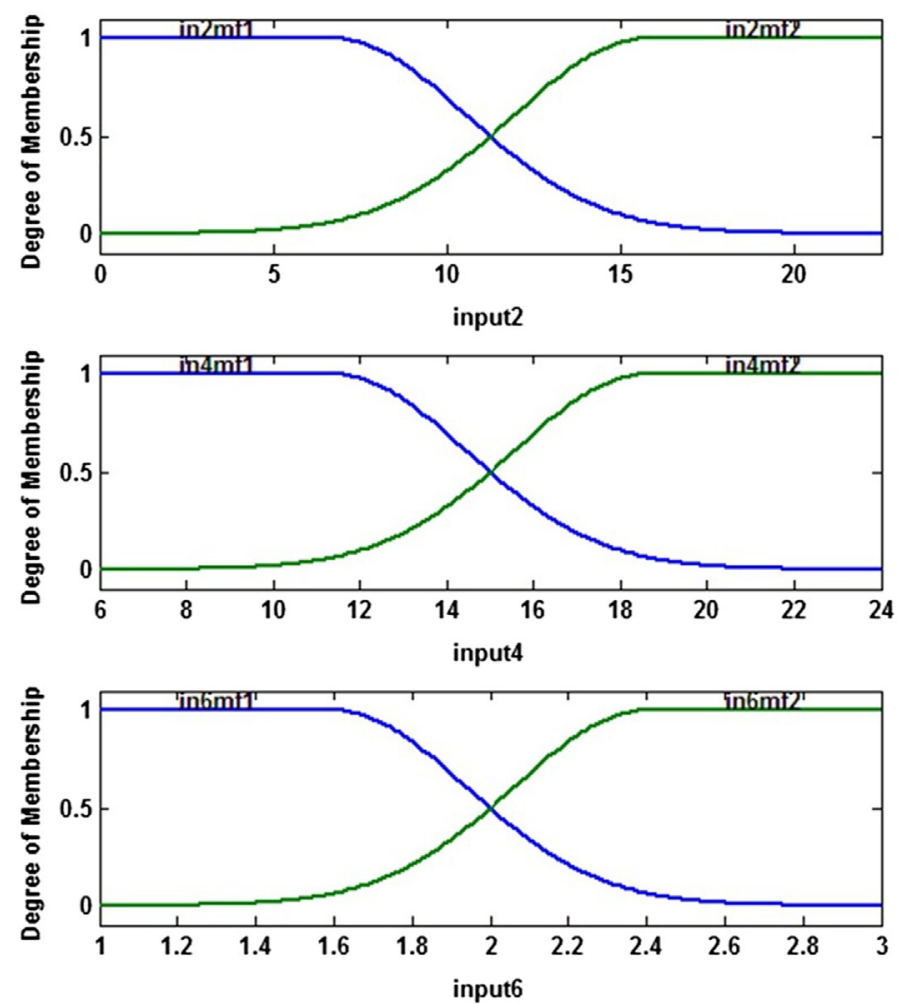

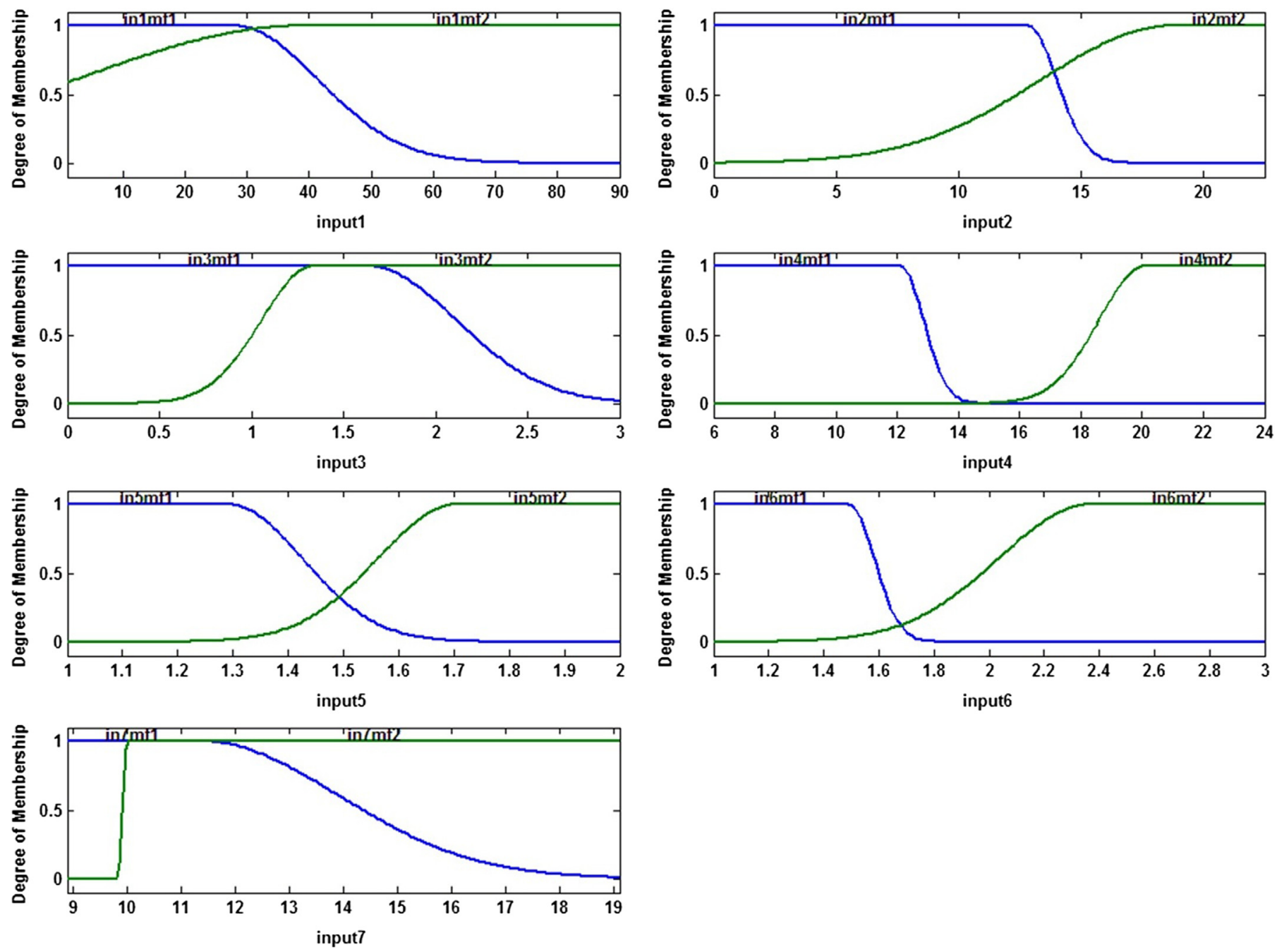

Fig. 8. Final membership functions for compressive strength (input $1=$ curing time(days); input $2=\mathrm{Ca}(\mathrm{OH})_{2}$ content (wt $\%$ ); input $3=$ the amount of superplasticizer (wt $\%$ ); input $4=\mathrm{NaOH}$ concentration $(\mathrm{M})$; input5 = mold type; input $6=$ aluminosilicate source; and input7 $=\mathrm{H}_{2} \mathrm{O} / \mathrm{Na}_{2} \mathrm{O}$ molar ratio).

$\mathrm{MAPE}=\frac{1}{n} \sum_{i}\left|\frac{t_{i}-o_{i}}{t_{i}}\right| \times 100$

$\mathrm{MSE}=\frac{1}{n} \sum_{i}\left(t_{i}-o_{i}\right)^{2}$

where $t, o$ and $n$ are the target value, the output value and the number of data sets in each training and testing phases.

The calculated performance values for the proposed ANFIS model have been presented in Table 1 . The values of $R^{2}$, MAPE and MSE in training phase of the model are 0.94, 11.52 and 14.48 , respectively while these values in testing phase are $0.92,15.89$ and 23.69, respectively. These values together with the results illustrated in Fig. 6 show that the proposed ANFIS models could predict the compressive strength of the considered geopolymers appropriately. However, the predicted compressive strength for two geopolymeric mixtures with compressive strengths of about 56 and $68 \mathrm{MPa}$ have the most deviation in the model. Although, some deviation is observed for some of the other data, the values predicted by the model have accuracy more than $90 \%$ and one may propose the presented model as a suitable one for prediction the compressive strength of the considered geopolymers.

A comparison between the predicted results by the proposed ANFIS model in this study and that of the previous work [31] shows that both ANNs models and ANFIS could predict the compressive strength of the evaluated geopolymers well.

Since the presented soft-computing techniques are limited to those presented in the previous works (see for example [31-33]), it is not possible to present a comprehensive evaluation with different geopolymeric specimens. However, all of the proposed models in the previous work and that presented in this work show that such soft-computing methods as ANFIS, ANNs and GP could be suitably adopted for predicting the properties of geopolymeric specimens.

The 3D interaction graph between some of selected variables generated by the proposed model can be seen in Fig. 10 . Fig. 10a shows the interaction between $\mathrm{H}_{2} \mathrm{O} / \mathrm{Na}_{2} \mathrm{O}$ ratio and $\mathrm{NaOH}$ concentration on compressive strength of the considered geopolymers. The results show that the highest strength has been achieved in higher concentration of $\mathrm{NaOH}$ and lower $\mathrm{H}_{2} \mathrm{O} / \mathrm{Na}_{2} \mathrm{O}$ ratio. This is in accordance to the previous work 


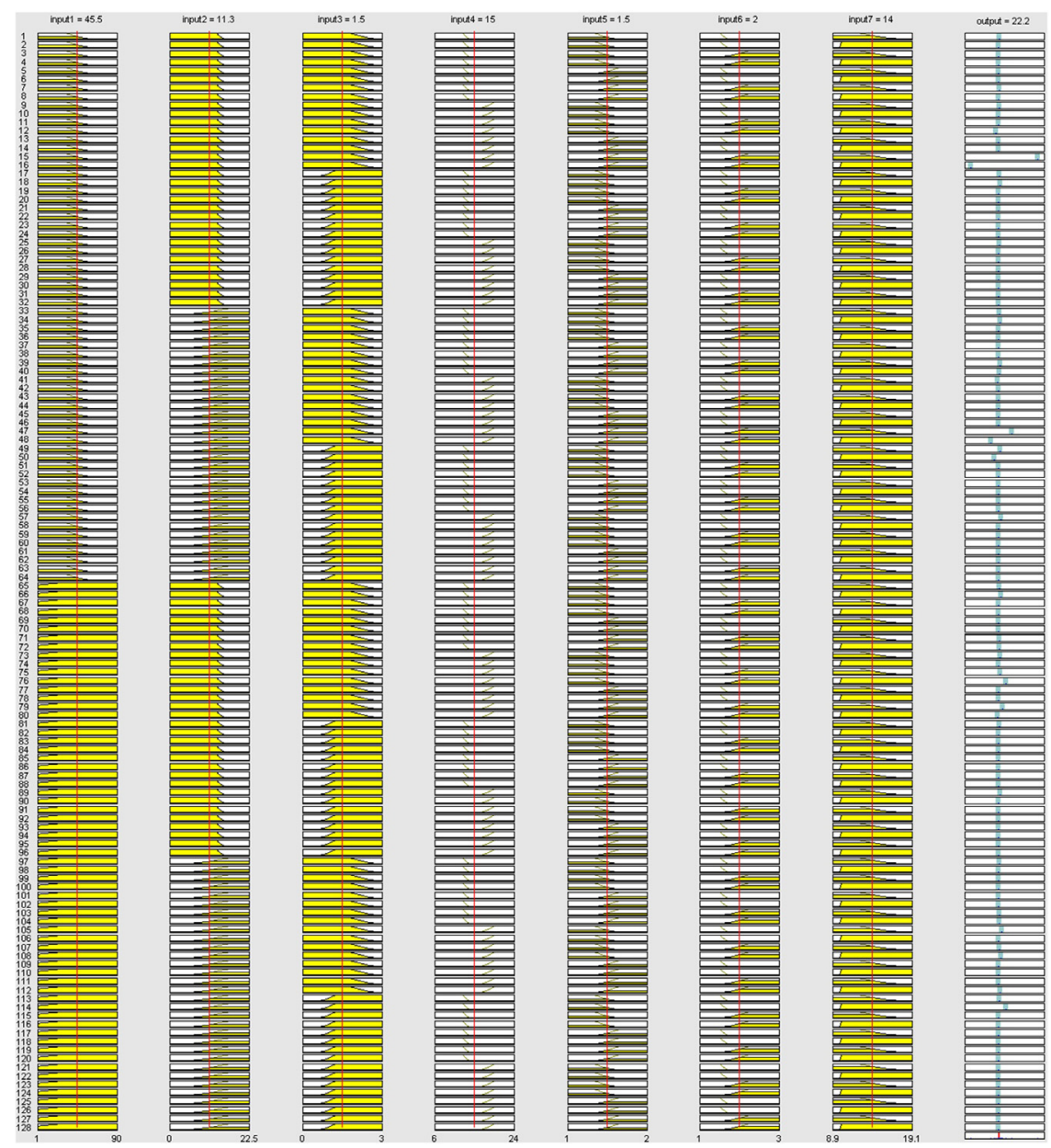

Fig. 9. Fuzzy inference diagram for compressive strength.

[31]. Strength of a geopolymeric mixture depends on several factors in which $\mathrm{NaOH}$ concentration has a significant effect. However, the effect of $\mathrm{NaOH}$ concentration on compressive strength of geopolymers is completely antithesis. While some reported the increased strength with high $\mathrm{NaOH}$ concentration $[11,44,45]$, the others $[46,47]$ showed the negative impact of high $\mathrm{NaOH}$ concentration. An investigation on the proposed $\mathrm{NaOH}$ concentration for production geopolymers with higher strength shows that this depends mainly on the aluminosilicate source [48]. This has been completely evident in Fig. 10b where for type 1 aluminosilicate source even at low $\mathrm{NaOH}$ concentration, the strength is high and in some cases for this source type, the strength has been decreased by the increased $\mathrm{NaOH}$ concentration. However, the results of the three sources in this work show that the strength and $\mathrm{NaOH}$ increments behave in a parallel manner.

Fig. 10c shows the interaction between $\mathrm{NaOH}$ concentration and the amount of superplasticizer. The figure shows that higher amount of superplasticizer at all $\mathrm{NaOH}$ concentrations resulted in higher strengths. This is in accordance to the previous work [31], where higher content of superplasticizer usage lead to the reduced required water and hence increased strength. This is completely established for concrete specimens and since the nature of these constructional materials is similar, one may anticipate that geopolymers behave in the same manner.

One of the most interesting findings by the proposed ANFIS model has been illustrated in Fig. 10d where the interaction between $\mathrm{Ca}(\mathrm{OH})_{2}$ content and $\mathrm{NaOH}$ concentration has been presented. The figure shows that in all of $\mathrm{NaOH}$ concentration and high $\mathrm{Ca}(\mathrm{OH})_{2}$ content, the compressive strength is very low. The highest strengths have been achieved at intermediate $\mathrm{NaOH}$ concentrations and up to $10 \%$ of $\mathrm{Ca}(\mathrm{OH})_{2}$. The findings show that even at high $\mathrm{NaOH}$ concentration, excessive $\mathrm{Ca}$ $(\mathrm{OH})_{2}$ content may lead to the decreased strength. This is in accordance to [48] where geopolymers were produced by ordinary Portland cement (OPC) and high content of lime. Relatively low compressive strength of those geopolymers show the possible formation of $\mathrm{Ca}(\mathrm{OH})_{2}$ during incomplete geopolymerisation.

Finally, Fig. 10e-i shows the interaction between curing time and the other parameter. In all cases, it has been predicted that the compressive strength of the considered geopolymers increased up to 28 days and then will be decreased. This is in accordance to the previous work [31]. Although the conducted works on the post 28-days compressive strength of the geopolymers are limited, some of them have reported the decreased strength after 28 days of curing [44]. However, in 
a

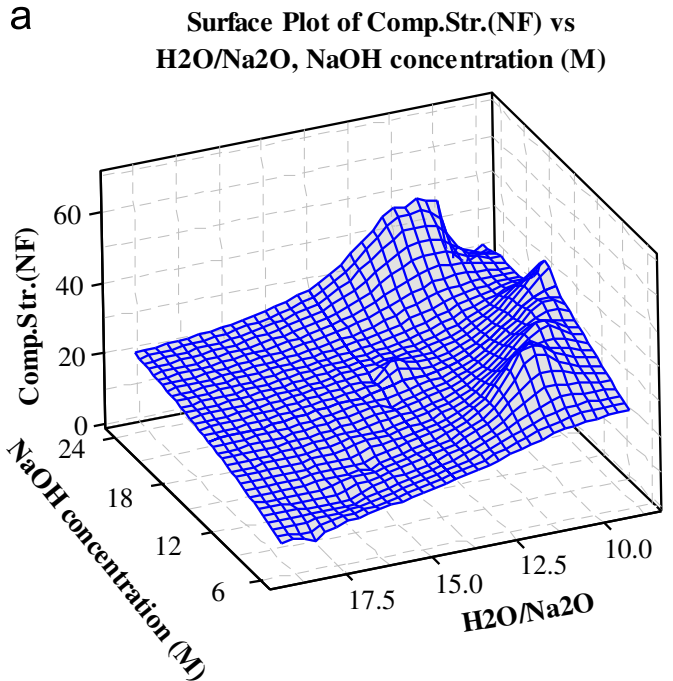

C

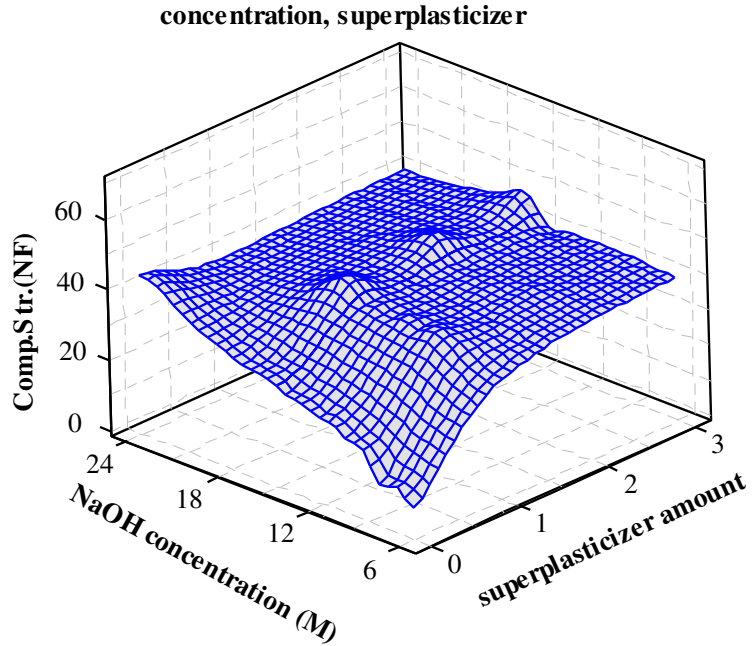

e

Surface Plot of Comp.Str.(NF) vs H2O/Na2O, Curing time (days)

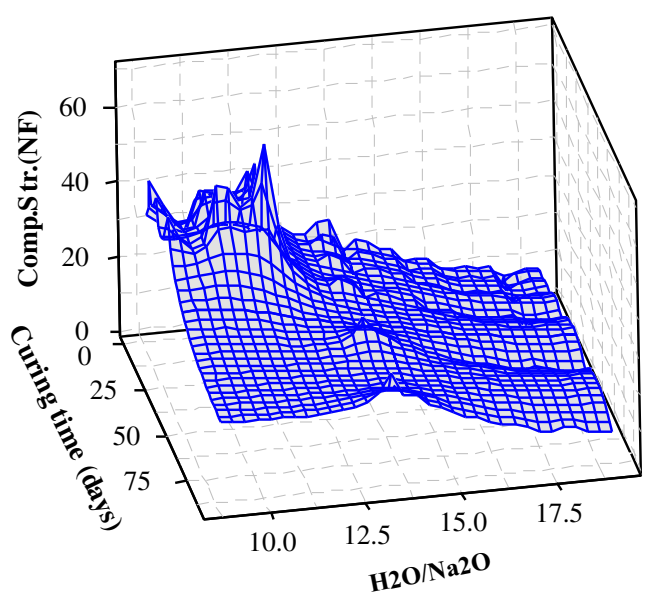

b $\begin{gathered}\text { Surface Plot of Comp.Str.(NF) vs } \\ \text { aluminosilicate, } \mathrm{NaOH} \text { concentration }\end{gathered}$

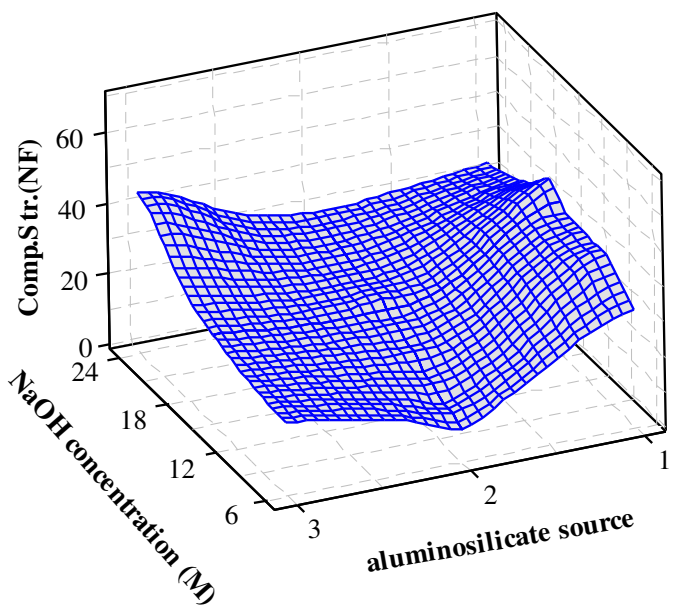

d Surface Plot of Comp.Str.(NF) vs $\mathrm{NaOH}$ concentration, $\mathrm{Ca}(\mathrm{OH}) 2$ Content

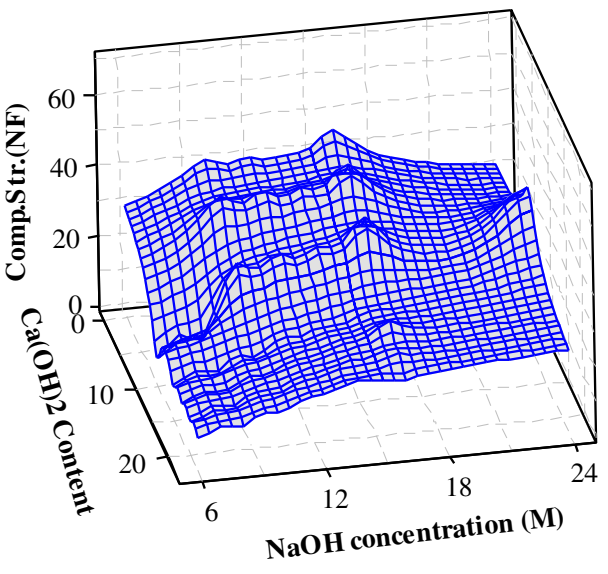

f

Surface Plot of Comp.Str.(NF) vs superplasticizer, aluminosilicate (days)

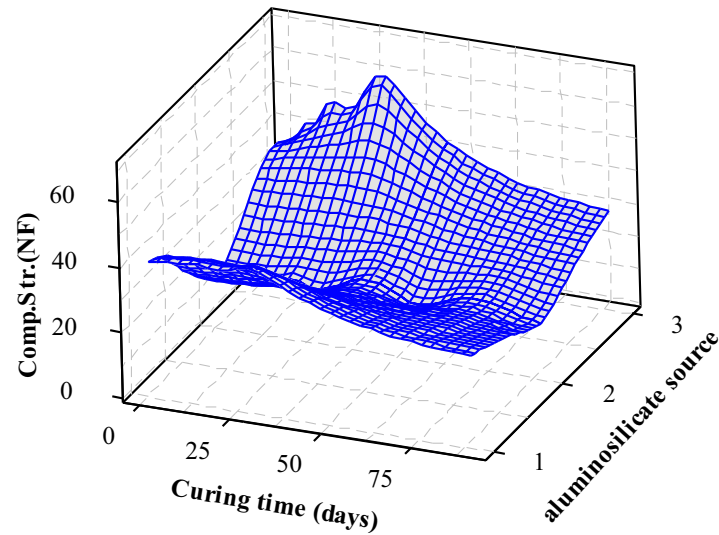

Fig. 10. The 3D interaction graph between some of selected variables generated by the proposed ANFIS model: (a) $\mathrm{NaOH}$ concentration and $\mathrm{H}_{2} \mathrm{O} / \mathrm{Na}_{2} \mathrm{O}$, (b) $\mathrm{NaOH}$ concentration and aluminosilicate source, (c) $\mathrm{NaOH}$ concentration and superplasticizer amount, (d) $\mathrm{NaOH}$ concentration and $\mathrm{Ca}(\mathrm{OH})_{2}$ content, (e) curing time and $\mathrm{H}_{2} \mathrm{O} / \mathrm{Na}_{2} \mathrm{O}$, (f) curing time and aluminosilicate source, (g) curing time and $\mathrm{NaOH}$ concentration, (h) curing time and superplasticizer amount, and (i) curing time and $\mathrm{Ca}(\mathrm{OH})_{2}$ content. 


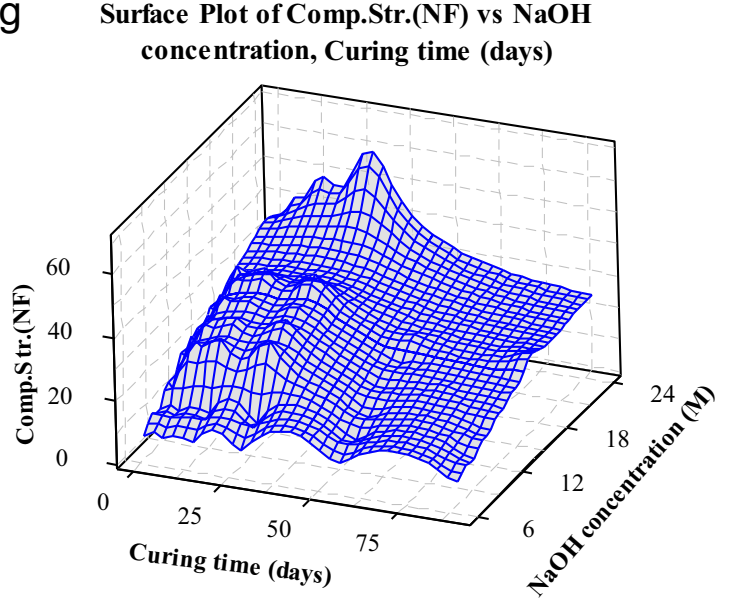

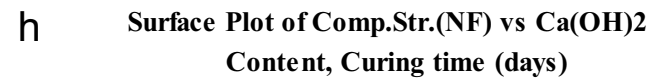

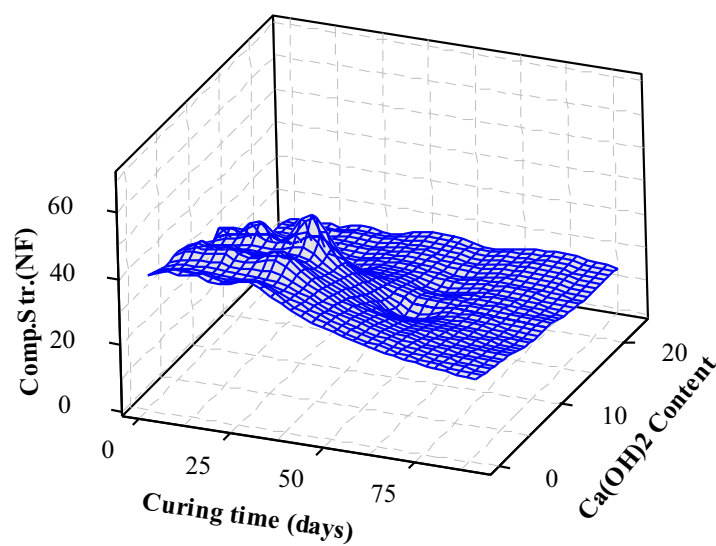

\section{i Surface Plot of Comp.Str.(NF) vs superplasticizer, Curing time (days)}

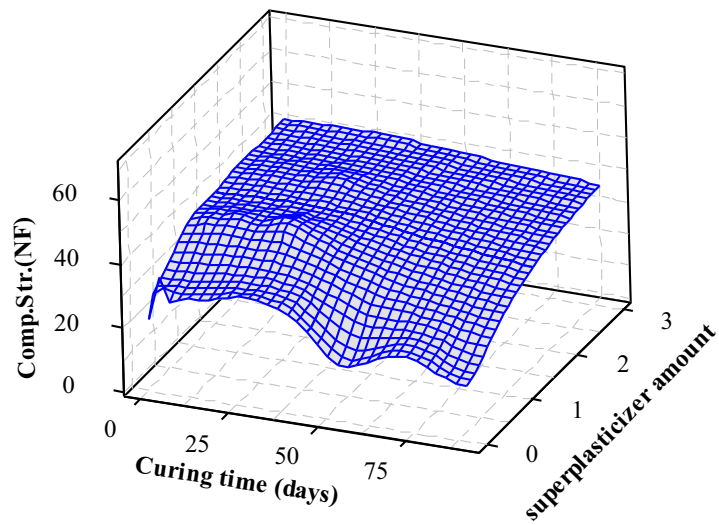

Fig. 10. (continued)

contrary, some reported the increased strength after 28 days of curing [47]. This may be related to the production method and aluminosilicate source and requires further investigations.

\section{Conclusion}

Application of neuro-fuzzy approaches for the prediction of compressive strength of the considered geopolymers is very scarce. This paper presents a pioneer work on neuro-fuzzy approach in this field. The proposed ANFIS model is a unified rule-based model based on experimental data. The proposed ANFIS models show very good agreement with experimental results. The values of $R^{2}$, MAPE and MSE in training phase of the model were acquired as $0.94,11.52$ and 14.48, respectively and $0.92,15.89$ and 23.69, respectively, in testing phase. The predicted results by the proposed ANFIS model showed that the effect of $\mathrm{NaOH}$ concentration as a main factor depends on the other factors. However, by considering the effect of the entire factors, the strength is decreased after 28 days of curing. As a conclusion of this study, neuro-fuzzy may serve as an effective alternative tool for the modeling compressive strength of geopolymers in the future.

\section{References}

[1] M. Romagnoli, C. Leonelli, E. Kamse, M.L. Gualtieri, Rheology of geopolymer by DOE approach, Constr. Build. Mater. 36 (2012) 251-258.

[2] K.-L. Lin, H.-S. Shiu, J.-L. Shie, T.-W. Cheng, C.-L. Hwang, Effect of composition on characteristics of thin film transistor liquid crystal display (TFT-LCD) waste glass-metakaolin-based geopolymers, Constr. Build. Mater. 36 (2012) 501-507.

[3] S. Ahmari, X. Ren, V. Toufigh, L. Zhang, Production of geopolymeric binder from blended waste concrete powder and fly ash, Constr. Build. Mater. 35 (2012) 718-729.

[4] C.Y. Heah, H. Kamarudin, A.M.Mustafa Al Bakri, M. Bnhussain, M. Luqman, I. Khairul Nizar, C.M. Ruzaidi, Y.M. Liew, Study on solids-to-liquid and alkaline activator ratios on kaolin-based geopolymers, Constr. Build. Mater. 35 (2012) 912-922.

[5] H.T. Kouamo, A. Elimbi, J.A. Mbey, C.J. Ngally Sabouang, D. Njopwouo, The effect of adding alumina-oxide to metakaolin and volcanic ash on geopolymer products: a comparative study, Constr. Build. Mater. 35 (2012) 960-969.

[6] H.T. Kouamo, J.A. Mbey, A. Elimbi, B.B. Kenne Diffo, D. Njopwouo, Synthesis of volcanic ash-based geopolymer mortars by fusion method: Effects of adding metakaolin to fused volcanic ash, Ceram. Int. 39 (2) (2013) 269-276.

[7] R. Rajamma, J.A. Labrincha, V.M. Ferreira, Alkali activation of biomass fly ash-metakaolin blends, Fuel 98 (2012) 265-271. 
[8] F. Pacheco-Torgal, D. Moura, Yining Ding, S. Jalali, Composition, strength and workability of alkali-activated metakaolin based mortars, Constr. Build. Mater. 25 (2011) 3732-3745.

[9] W.D.A. Rickard, J. Temuujin, A. van Riessen, Thermal analysis of geopolymer pastes synthesised from five fly ashes of variable composition, J. Non-Cryst.e Solids 358 (2012) 1830-1839.

[10] S. Onisei, Y. Pontikes, T. van Gerven, G.N. Angelopoulos, T. Velea, V. Predica, P. Moldovan, Synthesis of inorganic polymers using fly ash and primary lead slag, J. Hazard. Mater. 205-206 (2012) 101-110.

[11] A. Nazari, A. Bagheri., S. Riahi, Properties of geopolymer with seeded fly ash and rice husk bark ash, Mater. Sci. Eng. A 528 (2011) 7395-7401.

[12] P.K. Sarker, R. Haque, K.V. Ramgolam, Fracture behaviour of heat cured fly ash based geopolymer concrete, Mater. Des. 44 (2013) 580-586.

[13] X.S. Shi, F.G. Collins, X.L. Zhao, Q.Y. Wang, Mechanical properties and microstructure analysis of fly ash geopolymeric recycled concrete, J. Hazard. Mater. 237-238 (2012) 20-29.

[14] A.S. de Vargas, D.C.C. Dal Molin, A.C.F. Vilela, F.J. da Silva, B. Pavão e, H. Veit, The effects of $\mathrm{Na}_{2} \mathrm{O} / \mathrm{SiO}_{2}$ molar ratio, curing temperature and age on compressive strength, morphology and microstructure of alkaliactivated fly ash-based geopolymers, Cem. Concr. Compos. 33 (2011) 653-660.

[15] F. Pacheco-Torgal, J. Castro-Gomes, S. Jalali, Investigations about the effect of aggregates on strength and microstructure of geopolymeric mine waste mud binders, Cem. Concr. Res. 37 (2007) 933-941.

[16] K.-H. Yang, A.-R. Cho, J.-K. Song, Effect of water-binder ratio on the mechanical properties of calcium hydroxide-based alkali-activated slag concrete, Constr. Build. Mater. 29 (2012) 504-511.

[17] H. El-Didamony, A.A. Amer, H.A. Ela-ziz, Properties and durability of alkali-activated slag pastes immersed in sea water, Ceram. Int. 38 (2012) 3773-3780.

[18] S. Kumar, R. Kumar, S.P. Mehrotra, Influence of granulated blast furnace slag on the reaction, structure and properties of fly ash based geopolymer, J. Mater. Sci. 45 (2010) 607-615.

[19] A.R. Boğa, M. Öztürk, İ.B. Topçu, Using ANN and ANFIS to predict the mechanical and chloride permeability properties of concrete containing GGBFS and CNI, Compos. Part B: Eng. 45 (1) (2013) 688-696.

[20] J. Garzón-Roca, C.O. Marco, J.M. Adam, Compressive strength of masonry made of clay bricks and cement mortar: estimation based on Neural networksand fuzzy logic, Eng. Struct. 48 (2013) 21-27.

[21] A. Cevik, Modeling strength enhancement of FRP confined concrete cylinders using soft computing, Expert Syst. Appl. 28 (5) (2011) 5662-5673.

[22] J.L. Pérez, A. Cladera, J.R. Rabuñal, F. Martínez-Abella, Optimization of existing equations using a new Genetic Programming algorithm: application to the shear strength of reinforced concrete beams, Adv. Eng. Softw. 50 (2012) 82-96.

[23] H. Tanyildizi, A. Çevik, Modeling mechanical performance of lightweight concrete containing silica fume exposed to high temperature using genetic programming, Constr. Build. Mater. 24 (12) (2010) 2612-2618.

[24] A. Nazari, S. Riahi, Computer-aided prediction of the $\mathrm{ZrO}_{2}$ nanoparticles' effects on tensile strength and percentage of water absorption of concrete specimens, J. Mater. Sci. Technol. 28 (1) (2012) 83-96.

[25] A. Cevik, M.T. Göğüş, İ.H. Güzelbey, H. Filiz, Soft computing based formulation for strength enhancement of CFRP confined concrete cylinders, Ad. Eng. Softw. 41 (4) (2010) 527-536.

[26] A.T.A. Dantas, M.B. Leite, K. de J. Nagahama, Prediction of compressive strength of concrete containing construction and demolition waste using artificial neural networks, Constr. Build. Mater. 38 (2013) 717-722.

[27] B. Ahmadi-Nedushan, Prediction of elastic modulus of normal and high strength concrete using ANFIS and optimal nonlinear regression models, Constr. Build. Mater. 36 (2012) 665-673.
[28] R. Madandoust, J.H. Bungey, R. Ghavidel, Prediction of the concrete compressive strength by means of core testing using GMDH-type neural network and ANFIS models, Comput. Mater. Sci. 51 (1) (2012) 261-272.

[29] J. Amani, R. Moeini, Prediction of shear strength of reinforced concrete beams using adaptive neuro-fuzzy inference system and artificial neural network, Sci. Iran. 19 (2) (2012) 242-248.

[30] J. Sobhani, A.A. Ramezanianpour, Service life of the reinforced concrete bridge deck in corrosive environments: a soft computing system, Appl. Soft Comput. 11 (4) (2011) 3333-3346.

[31] A. Nazari, F. Pacheco, Torgal, Predicting compressive strength of different geopolymers by artificial neural networks, Ceram. Int. 39 (3) (2013) 2247-2257, http://dx.doi.org/10.1016/j.ceramint.2012.08.070.

[32] A. Nazari, S. Riahi, Experimental investigations and ANFIS prediction of water absorption of geopolymers produced by waste ashes, J. Non-Cryst. Solids 358 (1) (2012) 40-46.

[33] A. Nazari, M. Ghafouri Safarnejad, Prediction early age compressive strength of OPC-based geopolymers with different alkali activators and seashell powder by gene expression programming, Ceram. Int. 39 (2) (2013) 1433-1442.

[34] J.S.R. Jang, ANFIS: adaptive-network-based fuzzy inference system, IEEE Trans. Syst. Man Cyber. 23 (3) (1993) 665-685.

[35] F. Pacheco-Torgal, J.P. Castro-Gomes, S. Jalali, Investigations on mix design of tungsten mine waste geopolymeric binder, Constr. Build. Mater. 22 (2008) 1939-1949.

[36] A. Lotfi Zadeh, Fuzzy set, Inform. Control 8 (1965) 338-353.

[37] L. Rutkowski, Flexible Neuro-Fuzzy Systems: Structures, Learning and Performance Evaluation, Springer, 2004.

[38] S.N. Sivanandam, S. Sumathi, S.N. Deepa, Introduction to Fuzzy Logic using MATLAB, Springer, 2007.

[39] J. Haris, Fuzzy Logic Applications in Engineering Science, Springer, 2006.

[40] Y.Y. Bai, H. Zhuang, D. Wang, Advanced Fuzzy Logic Technologies in Industrial Applications, Springer, 2006.

[41] J.S.R. Jang, C.T. Sun, E. Mizutani, Neuro-fuzzy and soft computing. a computational approach to learning and machine intelligence, Prentice Hall, 1997.

[42] M. Sonebi, A. Cevik, Prediction of Fresh and Hardened Properties of Self-Consolidating Concrete Using Neurofuzzy Approach, J. Mater. Civil Eng. 21 (11) (2009) 672-679.

[43] I.H. Guzelbey, A. Cevik, A. Erklig, Prediction of web crippling strength of cold-formed steel sheetings using neural Networks, J. Constr. Steel Res. 62 (2006) 962-973.

[44] J. Wongpa, K. Kiattikomol, C. Jaturapitakkul, P. Chindaprasirt, Compressive strength, modulus of elasticity, and water permeability of inorganic polymer concrete, Mater. Des. 31 (2010) 4748-4754.

[45] Z. Zuhua, Y. Xiao, Z. Huajun, C. Yue, Role of water in the synthesis of calcined kaolin-based geopolymer, Appl. Clay Sci. 43 (2) (2009) 218-223.

[46] P. Chindaprasirt, T. Chareerat, V. Sircicatnanon, Workability and strength of coarse high calcium fly ash geopolymer, Cem. Concr. Compos. 29 (2007) 224-229.

[47] K. Somna, C. Jaturapitakkul, P. Kajitvichyanukul, P. Chindaprasirt, $\mathrm{NaOH}$-activated ground fly ash geopolymer cured at ambient temperature, Fuel 90 (6) (2011) 2118-2124.

[48] A. Nazari, H. Khanmohammadi, M. Amini, H. Hajiallahyari, A. Rahimi, Production geopolymers by Portland cement: designing the main parameters' effects on compressive strength by Taguchi method, Materi. Des. 41 (2012) 43-49. 